\title{
木質材料に使われる接着剤のインベントリ分析*1
}

\author{
澤田幸伸 $* 2,3$ ，安藤恵介*2，服部順昭*2，田村靖夫*4
}

\section{Inventory Analysis of Adhesives Used for Wood Based Materials*1}

\author{
Yukinobu SAWADA *2,3, Keisuke ANDO*2, \\ Nobuaki HATTORI ${ }^{* 2}$ and Yasuo TAMURA*4
}

\begin{abstract}
Five popular adhesives of urea resin (UF), melamine-urea cocondensed resin (MUF), phenol resin (PF), phenolresorcinol resin (PRF), and aqueous polymer isocyanate (API) for wood based materials were analyzed by the inventory analysis. It was calculated that energy consumption and emissions of $\mathrm{CO}_{2}$, $\mathrm{NOx}$ and $\mathrm{SOx}$ for production of $1 \mathrm{~kg}$ resin using unit processes from oil drilling for material's production to resin production. It became clear that MUF and PRF consumed the largest amount of energy and exhausted maximum amount of SOx among five adhesives. On the other hand, UF consumed the least energy and exhausted minimum SOx which are equivalent to the range of 57 and 67 percents of those of MUF and PRF, respectively. PF and API were recognized to be medium ones among five adhesives analyzed. $\mathrm{CO}_{2}$ and NOx emissions of API were remarkably large in such a condition that these amounts were more than six times as long as other resins.

It was highly recommended that environmental loads of an adhesive should be judged by not the weight unit but the functional unit in case of life cycle assessment of wood based materials.
\end{abstract}

Keywords : inventory analysis, formaldehyde resin, phenol resin, resorcinol resin, aqueous polymer isocyanate.

木質材料に使われる主な接着剤 5 種類〔ユリア樹脂接着剤 (UF)，メラミン・ユリア共縮合樹 脂接着剂 (MUF)，フェノール樹脂接着剂 (PF)，レゾルシノール樹脂接着剂 (PRF), 水性高分 子イソシアネート系接着剤（API）]のインベントリ分析を行った。接着剤 $1 \mathrm{~kg}$ の製造に必要な 資源の調達から原料の製造と輸送，接着剂製造までのエネルギー消費量, $\mathrm{CO}_{2}$ 排出量, $\mathrm{NOx}$ 排出 量, SOx 排出量を算出した。その結果，MUF と PRF は共にエネルギー消費量と SOx 排出量が最 も多く, UF のそれらは両者の 57 7 $67 \%$ と最も少なくなることが分かった。API と PF は両者の中 間的な值となった。 $\mathrm{API}$ の $\mathrm{CO}_{2}$ と $\mathrm{NOx}$ の排出量は, 最も少ない UF の 6 倍以上と, 顕著に多かっ た。

今回得られた重量単位による接着剤の環境負荷量は, これによって接着剤の環境負荷に対する 優劣を判断するのではなく, 木質材料の機能単位を揃えた上での判断に供するためのものである。

*1 Received July 30, 2005; Accepted December 26, 2005. 本論文の一部は第53回日本木材学会大会（2003年 3 月，福岡） で発表した。

*2 東京農工大学大学院農学教育部 Graduate School of Agriculture, Tokyo University of Agriculture and Technology, Fucyu 183-8509

*3 Present address : 大建工業(株)開発研究所 Research and Development Center, Daiken Corp., Okayama 702-8045

*4 前秋田県立大学 Former Akita Prefectural University, Noshiro 016-0876 
1. 緒

製品の環境負荷量を評価する方法としてライフサ イクルアセスメント（以下，LCAという）が注目 されるようになり，様々な製品や原材料の環境負荷 量を求めるインベントリが実施されてきた。ところ が，金属やプラスチックなどに比べて，環境に優し いと言われている木質材料や木質製品に関するイン ベントリはほとんど行われて抢らず，定量的な評価 が望まれている

木質材料の LCA を行うには，その原材料調達か ら製造，廃棄に至る全ての工程を調べなければなら ない。しかし，海上輸送で消費される重油，製造装 置を稼動するための電力，乾燥に使われる燃料（木 材チップや重油）などの排出原単位は公表されてい るものの，木材や接着剤の排出原単位は整備されて いない。それ故，接着剤の原単位には代替樹脂のそ れを用いざるを得ないことになり，木質材料の環境 負荷評価が十分に行えない状況にある。

そこで，木質材料に広く使われているホルムアル デヒド系接着剂 4 種類〔ユリア樹脂接着剤 (UF), メラミン・ユリア共縮合樹脂接着剂 (MUF)，フェ ノール樹脂接着剤 (PF)，レゾルシノール樹脂接着 剂（PRF））と，ホルムアルデヒド問題とその規制 から近年生産量が増加している水性高分子イソシア ネート系接着剂（API）を対象として，接着剤 $1 \mathrm{~kg}$ の製造に必要な資源の調達から原料の製造と輸送, 接着剤製造までのインプットとアウトプットを調 べ，接着剤の環境負荷量を算出した。接着剤の呼称 については以後上記の略称を用いることにする。

\section{2. 調 査}

インベントリ分析の対象とした接着剤は，4 種類 のホルムアルデヒド系接着剤 (UF, MUF, PF, PRF）とAPI である。用いた接着剤の原料とその配 合量は，原則として接着剂メーカーで1975年から 1995年まで採用されていた処方箋に従ったが，文 献 ${ }^{4-6)}$ による值も一部で参照した。接着剂反応時の 電力と熱の使用量は，接着剂メーカーへの聞き取り 調査により，代表値を算出して用いた。

接着剤は木質材料にとっては原料の一つであり， その用途によって用いられる接着剤の種類や濃度, 増量剂の量といった配合，さらには塗布量が異なる ため，ここでは，固形分ではなく水溶液べースの接 着剂 $1 \mathrm{~kg}$ のメーカにおける製造までを調查範囲と した。なお，固形分の割合と原料並びに消費エネル ギーを分けて示したので，接着凨製造を木質材料製 造現場で行う場合にもこれらのデー夕が活用できる よう配慮した。環境負荷項目は，すべての原材料に ついて統一する必要があることから，エネルギー消 費量, $\mathrm{CO}_{2}$ 排出量, NOx 排出量, SOx 排出量の 4 種 類とした。

対象とした 5 種類の接着剤の原料および電力の排 出原単位を Table 1 にまとめた。ホルムアルデヒド や炭酸ナトリウム, アンモニア, 水酸化ナトリウム, ポリビニルアルコール（以下， PVA という)，パラ ホルムアルデヒドは水溶液で用いられているが，そ の濃度は様々であったので，水溶液で表示されてい る原単位を固形分に換算しこここでの原単位とした。 スチレンブタジエンラバー（以下，SBR という）に ついても，ラテックスではなく固形分の原単位とし

Table 1. Energy consumption and emission per unit used in this paper.

\begin{tabular}{lccccc}
\hline \hline \multicolumn{1}{c}{ Material } & Unit & $\begin{array}{c}\text { Energy consumption } \\
(\mathrm{MJ})\end{array}$ & $\begin{array}{c}\mathrm{CO}_{2} \text { emission } \\
\left(\mathrm{kg}-\mathrm{CO}_{2}\right)\end{array}$ & $\begin{array}{c}\text { NOx emission } \\
(\mathrm{g}-\mathrm{NOx})\end{array}$ & $\begin{array}{c}\text { SOx emission } \\
(\mathrm{g}-\mathrm{SOx})\end{array}$ \\
\hline Electricity $^{7)}$ & $\mathrm{kWh}$ & $7.64 \mathrm{E}+00$ & $4.32 \mathrm{E}-01$ & $2.72 \mathrm{E}-01$ & $3.70 \mathrm{E}-01$ \\
$\mathrm{LPG}^{7)}$ & $\mathrm{kg}$ & $4.64 \mathrm{E}+01$ & $3.34 \mathrm{E}+00$ & $1.90 \mathrm{E}-03$ & $3.00 \mathrm{E}-03$ \\
$\mathrm{Urea}^{8)}$ & $\mathrm{kg}$ & $2.45 \mathrm{E}+01$ & $2.75 \mathrm{E}-01$ & $4.96 \mathrm{E}-01$ & $5.80 \mathrm{E}-01$ \\
Melamine $^{8)}$ & $\mathrm{kg}$ & $5.13 \mathrm{E}+01$ & $7.85 \mathrm{E}-01$ & $1.44 \mathrm{E}+00$ & $1.20 \mathrm{E}+00$ \\
Phenol $^{7)}$ & $\mathrm{kg}$ & $5.27 \mathrm{E}+01$ & $9.61 \mathrm{E}-01$ & $1.80 \mathrm{E}+00$ & $1.40 \mathrm{E}+00$ \\
Resorcinol $^{9)}$ & $\mathrm{kg}$ & $8.75 \mathrm{E}+01$ & $2.77 \mathrm{E}+00$ & $5.69 \mathrm{E}+00$ & $2.68 \mathrm{E}+00$ \\
Formaldehyde $^{7)}$ & $\mathrm{kg}$ & $3.34 \mathrm{E}+01$ & $-3.38 \mathrm{E}-02$ & $-3.92 \mathrm{E}-01$ & $1.85 \mathrm{E}+00$ \\
Paraformaldehyde $^{9)}$ & $\mathrm{kg}$ & $5.37 \mathrm{E}+01$ & $2.30 \mathrm{E}+00$ & $4.66 \mathrm{E}+00$ & $3.19 \mathrm{E}+00$ \\
Methanol $^{7)}$ & $\mathrm{kg}$ & $3.26 \mathrm{E}+01$ & $2.11 \mathrm{E}-01$ & $2.61 \mathrm{E}-01$ & $1.80 \mathrm{E}+00$ \\
Sodium hydroxide $^{7)}$ & $\mathrm{kg}$ & $4.59 \mathrm{E}+00$ & $5.73 \mathrm{E}-01$ & $4.83 \mathrm{E}-01$ & $1.00 \mathrm{E}+00$ \\
Ammonia $^{7)}$ & $\mathrm{kg}$ & $3.82 \mathrm{E}+01$ & $1.45 \mathrm{E}-01$ & $1.90 \mathrm{E}-01$ & $8.12 \mathrm{E}-01$ \\
Polyvinylalcohol $^{9)}$ & $\mathrm{kg}$ & $6.67 \mathrm{E}-01$ & $3.30 \mathrm{E}+00$ & $3.29 \mathrm{E}+00$ & $1.04 \mathrm{E}+00$ \\
$\mathrm{MDI}^{7)}$ & $\mathrm{kg}$ & $5.82 \mathrm{E}+01$ & $1.40 \mathrm{E}+00$ & $1.90 \mathrm{E}+00$ & $2.10 \mathrm{E}+00$ \\
$\mathrm{SBR}^{7)}$ & $\mathrm{kg}$ & $9.28 \mathrm{E}+01$ & $3.31 \mathrm{E}+00$ & $6.56 \mathrm{E}+00$ & $2.90 \mathrm{E}+00$ \\
\hline
\end{tabular}


た。レゾルシノール，パラホルムアルデヒド， PVA の原単位は産業技術総合研究所 LCA 研究センター の資料を用いた。電力の排出原単位は, 電力会社に より発電事情が異なることと接着剤の生産地域が限 定できないことから，受電端に扔ける $1 \mathrm{~kW}$ 使用時 の日本平均排出原単位を用いた。

ホルムアルデヒドと水酸化ナトリウムについて は, 製造時に蒸気や水素ガスが副産物として発生し, それらは別の製品の製造に使用されることから，そ の分の負荷量を控除した原単位となっている。例え ば，Table 1 で，ホルムアルデヒド製造における $\mathrm{CO}_{2}$
やNOx の排出量が負になっているのは，このため である。なお，控除分がどの程度になるかを知るた めに，副産物の配分を考慮しない原単位も求めた。

\section{3. 結果と考察}

\section{1 接着剤のインベントリ}

接着剂を水溶液ベースで $1 \mathrm{~kg}$ 製造するまでに消 費したエネルギー量と環境負荷量並びに項目毎の総 和に占める百分率を, 原料別投入量と共に, Table 2-6に示した。表中の環境負荷量は, 原料の投入量 に Table 1 の原単位を乗じて算出した值である。ギ

Table 2. Inventory analysis to produce $1 \mathrm{~kg}$ of urea resin (UF).

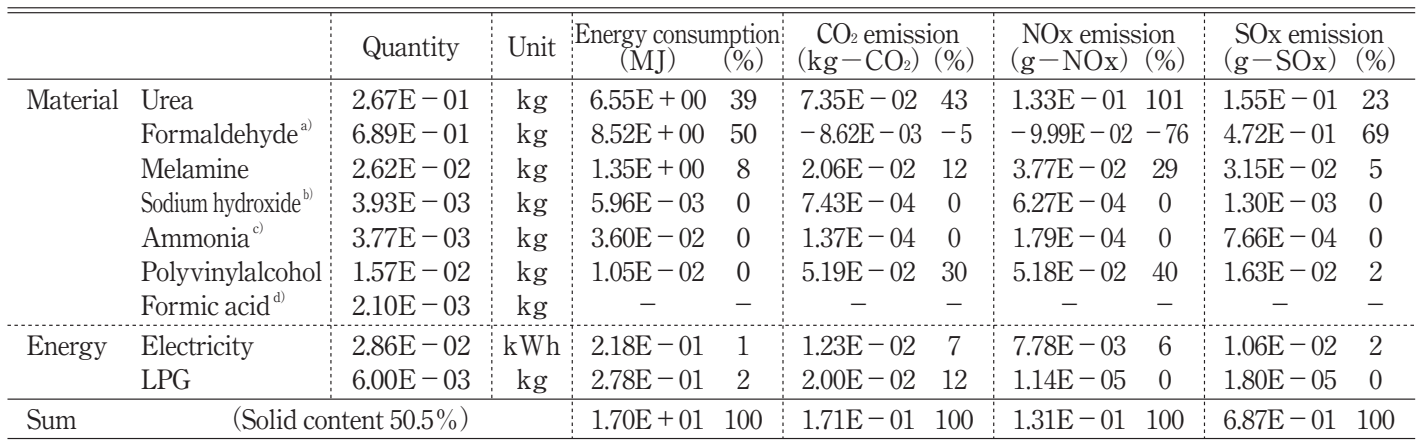

a) $37 \%$ aqueous solution

b) $33 \%$ aqueous solution

c) $25 \%$ aqueous solution

d) $11.7 \%$ aqueous solution

Table 3. Inventory analysis to produce $1 \mathrm{~kg}$ of melamine-urea cocondensed resin (MUF).

\begin{tabular}{|c|c|c|c|c|c|c|c|c|c|c|c|}
\hline \multirow{2}{*}{ Material } & \multirow[b]{2}{*}{ Melamine } & \multirow{2}{*}{$\begin{array}{c}\text { Quantity } \\
2.06 \mathrm{E}-01\end{array}$} & \multirow{2}{*}{$\begin{array}{c}\text { Unit } \\
\mathrm{kg}\end{array}$} & \multicolumn{2}{|c|}{$\begin{array}{l}\text { Energy consumption } \\
(\mathrm{MJ}) \\
(\%)\end{array}$} & \multicolumn{2}{|c|}{$\begin{array}{l}\mathrm{CO}_{2} \text { emission } \\
\left(\mathrm{kg}-\mathrm{CO}_{2}\right)(\%)\end{array}$} & \multicolumn{2}{|c|}{$\begin{array}{l}\text { NOx emission } \\
(\mathrm{g}-\mathrm{NOx})(\%)\end{array}$} & \multicolumn{2}{|c|}{$\begin{array}{l}\text { SOx emission } \\
(\mathrm{g}-\mathrm{SOx})(\%)\end{array}$} \\
\hline & & & & $1.06 \mathrm{E}+01$ & 40 & $1.62 \mathrm{E}-01$ & 48 & $2.96 \mathrm{E}-01$ & 60 & $2.47 \mathrm{E}-01$ & 24 \\
\hline & Urea & $1.01 \mathrm{E}-01$ & $\mathrm{~kg}$ & $2.48 \mathrm{E}+00$ & 10 & $2.79 \mathrm{E}-02$ & 8 & $5.03 \mathrm{E}-02$ & 10 & $5.88 \mathrm{E}-02$ & 6 \\
\hline & Formaldehyde $^{\text {a) }}$ & $5.10 \mathrm{E}-01$ & $\mathrm{~kg}$ & $6.31 \mathrm{E}+00$ & 24 & $-6.38 \mathrm{E}-03$ & -2 & $-7.40 \mathrm{E}-02$ & -15 & $3.49 \mathrm{E}-01$ & 34 \\
\hline & Paraformaldehyde ${ }^{e}$ & $4.82 \mathrm{E}-02$ & $\mathrm{~kg}$ & $7 \mathrm{E}+00$ & 8 & $8.86 \mathrm{E}-02$ & 27 & $1.80 \mathrm{E}-01$ & 36 & $1.23 \mathrm{E}-01$ & 12 \\
\hline & Methanol & $1.28 \mathrm{E}-01$ & $\mathrm{~kg}$ & $4.17 \mathrm{E}+00$ & 16 & $2.70 \mathrm{E}-02$ & 8 & $3.34 \mathrm{E}-02$ & 7 & $2.30 \mathrm{E}-01$ & 23 \\
\hline & Sodium hydroxide ${ }^{f)}$ & $1.86 \mathrm{E}-04$ & $\mathrm{~kg}$ & $8.54 \mathrm{E}-07$ & 0 & $1.07 \mathrm{E}-07$ & 0 & $8.99 \mathrm{E}-08$ & 0 & $1.86 \mathrm{E}-07$ & 0 \\
\hline & Ammonia ${ }^{\mathrm{g})}$ & $1.32 \mathrm{E}-03$ & $\mathrm{~kg}$ & $1.41 \mathrm{E}-02$ & 0 & $5.33 \mathrm{E}-05$ & 0 & $7.00 \mathrm{E}-05$ & 0 & $2.99 \mathrm{E}-04$ & 0 \\
\hline & Formic acid ${ }^{\mathrm{h})}$ & $1.08 \mathrm{E}-03$ & $\mathrm{~kg}$ & - & - & - & - & - & - & - & - \\
\hline & Sodium carbonate & $3.31 \mathrm{E}-03$ & $\mathrm{~kg}$ & - & - & - & - & - & - & - & - \\
\hline & Polyvinylalcohol & $7.44 \mathrm{E}-04$ & $\mathrm{~kg}$ & $4.97 \mathrm{E}-04$ & 0 & $2.46 \mathrm{E}-03$ & 1 & $2.45 \mathrm{E}-03$ & 0 & $7.72 \mathrm{E}-04$ & 0 \\
\hline Energy & Electricity & $2.86 \mathrm{E}-02$ & $\mathrm{kWh}$ & $2.18 \mathrm{E}-01$ & 1 & $1.23 \mathrm{E}-02$ & 4 & $7.78 \mathrm{E}-03$ & 2 & $1.06 \mathrm{E}-02$ & 1 \\
\hline & IDC & $6.00 \mathrm{E}-03$ & $\mathrm{~kg}$ & $2.78 \mathrm{E}-01$ & 1 & $2.00 \mathrm{E}-02$ & 6 & $1.14 \mathrm{E}-05$ & 0 & $1.80 \mathrm{E}-05$ & 0 \\
\hline Sum & \multicolumn{3}{|c|}{ (Solid content 55.8\%) } & $2.61 \mathrm{E}+01$ & 100 & $3.34 \mathrm{E}-01$ & 100 & $4.96 \mathrm{E}-01$ & 100 & $1.02 \mathrm{E}+00$ & 100 \\
\hline
\end{tabular}
a) $37 \%$ aqueous solution
e) $80 \%$ aqueous solution
f) $0.1 \%$ aqueous solution
g) $28 \%$ aqueous solution
h) $0.12 \%$ aqueous solution
i) $0.19 \%$ aqueous solution 
Table 4. Inventory analysis to produce $1 \mathrm{~kg}$ of phenol resin $(\mathrm{PF})$.

\begin{tabular}{|c|c|c|c|c|c|c|c|}
\hline & & Quantity & Unit & $\begin{array}{l}\text { Energy consumption } \\
\text { (MJ) (\%) }\end{array}$ & $\begin{array}{c}\mathrm{CO}_{2} \text { emission } \\
\left(\mathrm{kg}-\mathrm{CO}_{2}\right)(\%)\end{array}$ & $\begin{array}{l}\text { NOx emission } \\
(\mathrm{g}-\mathrm{NOx})(\%)\end{array}$ & $\begin{array}{l}\text { SOx emission } \\
(\mathrm{g}-\mathrm{SOx})(\%)\end{array}$ \\
\hline \multirow[t]{3}{*}{ Material } & Phe & $2.99 \mathrm{E}-01$ & $\mathrm{~kg}$ & $1.57 \mathrm{E}+01 \quad 70$ & $2.87 \mathrm{E}-0181$ & $5.38 \mathrm{E}-01 \quad 105$ & $4.18 \mathrm{E}-0150$ \\
\hline & Formaldehyde $^{a)}$ & $4.75 \mathrm{E}$ & $\mathrm{kg}$ & $5.88 \mathrm{E}+00 \quad 26$ & $-5.94 \mathrm{E}-03-2$ & $-6.89 \mathrm{E}-02-13$ & $3.25 \mathrm{E}-01 \quad 39$ \\
\hline & Sodium hydrox & $2.26 \mathrm{E}-01$ & $\mathrm{~kg}$ & $3.42 \mathrm{E}-01 \quad 2$ & $4.27 \mathrm{E}-02 \quad 12$ & $3.60 \mathrm{E}-02 \quad 7$ & $7.46 \mathrm{E}-02 \quad 9$ \\
\hline \multirow[t]{2}{*}{ Energy } & Electricity & $2.86 \mathrm{E}-02$ & $\mathrm{kWh}$ & $2.18 \mathrm{E}-01$ & $1.23 \mathrm{E}-02 \quad 3$ & $7.78 \mathrm{E}-03 \quad 2$ & $1.06 \mathrm{E}-02 \quad 1$ \\
\hline & & $6.00 \mathrm{E}-03$ & $\mathrm{~kg}$ & $2.78 \mathrm{E}-01 \quad 1$ & $2.00 \mathrm{E}-02 \quad 6$ & $1.14 \mathrm{E}-05 \quad 0$ & $1.80 \mathrm{E}-05 \quad 0$ \\
\hline Sum & \multicolumn{3}{|c|}{ (Solid content $48.1 \%$ ) } & $2.25 \mathrm{E}+01 \quad 100$ & $3.56 \mathrm{E}-01 \quad 100$ & $5.13 \mathrm{E}-01 \quad 100$ & $8.28 \mathrm{E}-01 \quad 100$ \\
\hline
\end{tabular}

a) $37 \%$ aqueous solution

b) $33 \%$ aqueous solution

Table 5. Inventory analysis to produce $1 \mathrm{~kg}$ of phenol-resorcinol resin (PRF).

\begin{tabular}{|c|c|c|c|c|c|c|c|}
\hline & & Quantity & Unit & $\begin{array}{l}\text { Energy consumption } \\
(\mathrm{MJ})\end{array}$ & $\begin{array}{l}\mathrm{CO}_{2} \text { emission } \\
\left(\mathrm{kg}-\mathrm{CO}_{2}\right)(\%)\end{array}$ & $\begin{array}{l}\text { NOx emission } \\
(\mathrm{g}-\mathrm{NOx})(\%)\end{array}$ & $\begin{array}{l}\text { SOx emission } \\
(\mathrm{g}-\mathrm{SOx})(\%)\end{array}$ \\
\hline \multirow[t]{6}{*}{ Material } & & $50 \mathrm{~F}-02$ & $\mathrm{~kg}$ & $5.01 \mathrm{E}+0017$ & $9.13 \mathrm{E}-02 \quad 14$ & $1.71 \mathrm{E}-01 \quad 14$ & $1.33 \mathrm{E}-01 \quad 13$ \\
\hline & & & $\mathrm{kg}$ & $6 \mathrm{E}+01 \quad 57$ & $5.26 \mathrm{E}-0178$ & $1.08 \mathrm{E}+00 \quad 86$ & $5.09 \mathrm{E}-01 \quad 48$ \\
\hline & hyde ${ }^{j)}$ & & $\mathrm{kg}$ & $2 \mathrm{E}+00 \quad 12$ & $-3.56 \mathrm{E}-03-1$ & $-4.13 E-02-3$ & $1.95 \mathrm{E}-01 \quad 18$ \\
\hline & & & $\mathrm{kg}$ & $3.71 \mathrm{E}+00 \quad 13$ & $2.40 \mathrm{E}-02 \quad 4$ & $2.97 \mathrm{E}-02 \quad 2$ & $2.05 \mathrm{E}-01 \quad 19$ \\
\hline & So & & $\mathrm{kg}$ & $3.74 \mathrm{E}-02 \quad 0$ & $4.67 \mathrm{E}-03 \quad 1$ & $3.94 \mathrm{E}-03 \quad 0$ & $8.15 \mathrm{E}-03 \quad 1$ \\
\hline & & & & - & - & - & - \\
\hline \multirow[t]{2}{*}{ Energy } & & 2 & $\mathrm{Wh}$ & $2.18 \mathrm{E}-01 \quad 1$ & $1.23 \mathrm{E}-02 \quad 2$ & $7.78 \mathrm{E}-03 \quad 1$ & $1.06 \mathrm{E}-02 \quad 1$ \\
\hline & & $6.00 \mathrm{E}-03$ & $\mathrm{~kg}$ & $2.78 \mathrm{E}-01 \quad 1$ & $2.00 \mathrm{E}-02 \quad 3$ & $1.14 \mathrm{E}-05 \quad 0$ & $1.80 \mathrm{E}-05 \quad 0$ \\
\hline Sum & \multicolumn{2}{|c|}{ (Solid content $54.0 \%$ ) } & & $2.94 \mathrm{E}+01100$ & $6.75 \mathrm{E}-01100$ & $1.25 \mathrm{E}+00 \quad 100$ & $1.06 \mathrm{E}+00100$ \\
\hline
\end{tabular}

j) $40.2 \%$ aqueous solution

b) $33 \%$ aqueous solution

Table 6. Inventory analysis to product $1 \mathrm{~kg}$ of aqueous polymer isocyanate (API).

\begin{tabular}{|c|c|c|c|c|c|c|c|}
\hline & & Quantity & Unit & $\begin{array}{l}\text { Energy consumption } \\
\text { (MJ) }(\%)\end{array}$ & $\begin{array}{c}\mathrm{CO}_{2} \text { emission } \\
\left(\mathrm{kg}-\mathrm{CO}_{2}\right)(\%)\end{array}$ & $\begin{array}{l}\text { NOx emission } \\
(\mathrm{g}-\mathrm{NOx})(\%)\end{array}$ & $\begin{array}{l}\text { SOx emission } \\
(\mathrm{g}-\mathrm{SOx})(\%)\end{array}$ \\
\hline \multirow{4}{*}{ Material } & Polyvinylalcohol $^{\mathrm{k})}$ & $5.75 \mathrm{E}-01$ & $\mathrm{~kg}$ & $3.84 \mathrm{E}-02 \quad 0$ & $1.90 \mathrm{E}-01 \quad 20$ & $1.89 \mathrm{E}-01 \quad 12$ & $5.96 \mathrm{E}-02 \quad 7$ \\
\hline & SBR & $1.72 \mathrm{E}-01$ & $\mathrm{~kg}$ & $1.60 \mathrm{E}+01 \quad 70$ & $5.71 \mathrm{E}-01 \quad 60$ & $1.13 \mathrm{E}+00 \quad 74$ & $5.00 \mathrm{E}-01 \quad 63$ \\
\hline & Calcium carbonate & $1.44 \mathrm{E}-01$ & $\mathrm{~kg}$ & $\begin{array}{ll}- & -\end{array}$ & - & $-\quad \quad-$ & - \\
\hline & MDI & $1.09 \mathrm{E}-01$ & $\mathrm{~kg}$ & $6.35 \mathrm{E}+00 \quad 28$ & $1.53 \mathrm{E}-01 \quad 16$ & $2.07 \mathrm{E}-01 \quad 14$ & $2.29 \mathrm{E}-01 \quad 29$ \\
\hline \multirow[t]{2}{*}{ Energy } & Electricity & $2.86 \mathrm{E}-02$ & $\mathrm{kWh}$ & $2.18 \mathrm{E}-01$ & $1.23 \mathrm{E}-02 \quad 1$ & $7.78 \mathrm{E}-03 \quad 1$ & $1.06 \mathrm{E}-02 \quad 1$ \\
\hline & LPG & $6.00 \mathrm{E}-03$ & $\mathrm{~kg}$ & $2.78 \mathrm{E}-01$ & $2.00 \mathrm{E}-02 \quad 2$ & $1.14 \mathrm{E}-05 \quad 0$ & $1.80 \mathrm{E}-05 \quad 0$ \\
\hline Sum & \multicolumn{3}{|c|}{ (Solid content $50.0 \%$ ) } & $2.29 \mathrm{E}+01 \quad 100$ & $9.46 \mathrm{E}-01100$ & $1.54 \mathrm{E}+00 \quad 100$ & $7.99 \mathrm{E}-01 \quad 100$ \\
\hline
\end{tabular}

k) $10 \%$ aqueous solution

酸，炭酸ナトリウム，炭酸カルシウム，フルフリル アルコールについては, その排出原単位が得られな かったので，その分の環境負荷量を過小評価してい ることになる。

ホルムアルデヒド系接着剤の環境負荷量は，何れ も投入量の多い主原料と排出原単位の大きい原料に よる負荷量が大きく影響していることが分かる。す なわち, UF や MUF, PF では尿素やホルムアルデ ヒド，メラミン，フェノールといった主原料と PVA やパラホルムアルデヒドといった排出原単位 の大きい原料による負荷量が大きいことが分かっ
た。一方，API では，SBR による負荷量がおよそ7 割近くとなった。

主原料製造までに要するエネルギー消費量や環境 負荷量は，データベースを遡って調べたところ，そ れらの原料を製造する際に用いられる主原料に大き く影響されること，その主原料のエネルギー消費量 や環境負荷量は最終的には原油の採掘と精製である ことが分かった。主原料以外に投入される原料は, $\mathrm{pH}$ の調整剂, 付加・縮合反応を促進する硬化剂, 接着剂の保存性, 仮接着性の向上など接着剂の性能 を高める添加剤である。これらの負荷量は主原料に 
比べ相対的に小さいが，メラミンや PVA は排出原 単位が大きく，接着剤全体の環境負荷量にある程度 影響することになる。

\section{2 接着剤の比較}

Fig. 1 にエネルギー消費量と環境負荷量を接着剤 別に比較した。これより，エネルギー消費量につい ては，PRF と MUF が最も大きく，次に PF と API が続き, UF が, PRF の約 6 割程度と, 最も小さか った。 $\mathrm{CO}_{2}$ 排出量については, API の負荷量が他の 接着剂に比べて著しく多く, 以下, PRF, PF, MUF，UF の順で小さくなった。NOx 排出量につい ては, $\mathrm{CO}_{2}$ 排出量と同様の傾向となった。 $\mathrm{SOx}$ 排出 量は，PRF と MUF が大きく，PF， API，UF の順に 小さくなった。この傾向は，エネルギー消費量と似 ているが，接着剤間の差はエネルギー消費量のそれ と比べて小さかった。

副産物製造に伴う環境負荷量を主産物，すなわち 接着剤原料で負担すると，エネルギー消費量や環境 負荷量は Fig. 2 のようになった。これより，ホルム
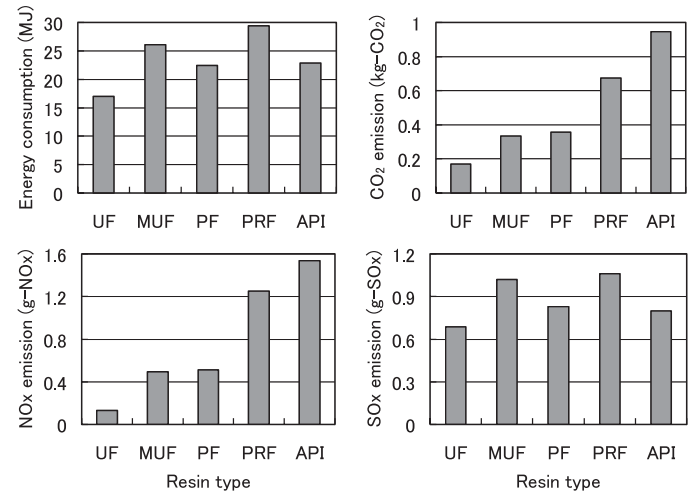

Fig. 1. Energy consumption and emissions for all resins.

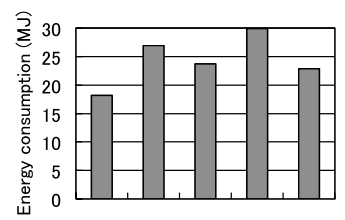

UF MUF PF PRF API

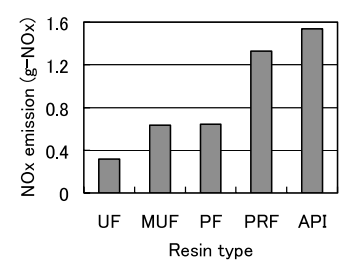

Fig. 2. Energy consumption and emissions for all resins when eliminating by-products.
アルデヒドと水酸化ナトリウムを原料として用いる 接着剤の負荷量が若干大きくなることが分かる。し かしながら, Fig. 1 における接着剤間の負荷量が入 れ替わるほど大きな差は出なかったことから，接着 剂製造の原単位としては，どちらを採用しても影響 は少ないと考える。ここでは, 用途は不明であるが, 副産物の環境負荷量をそれを用いる製品に負担させ る Fig. 1，すなわち Table 2-6 の結果を原単位として 用いることを推奨する。

\section{3 感度分析}

MUF と PRF については，それぞれ M/U 比，P/R 比の異なる製品が使い分けられている。実際に用い られている比の範囲で変化させて感度分析を行った 結果, Figs. 3，4 のようになった。 M/U 比や P/R 比 を変えると, エネルギー消費量や環境負荷量は変わ るが，他の接着剤との間で消費量が逆転するほど大 きな変化は見られなかった。よって，環境負荷量で 見た接着剂の位置付けは基本的には接着剂の種類に よって決まることが分かった。

\section{4. 結 論}

木質材料に用いられている 5 種類の接着剤の原料 採取から製造までの環境負荷量を算出した。その結 果, エネルギー消費量と SOx 排出量は MUF と PRF が同程度で最も多く, 次に API と PFが続き, UF の排出量は MUF や PRF の57〜 66\% と最も少なかっ た。 $\mathrm{CO}_{2}$ と $\mathrm{NOx}$ の排出量は, APIが, 最も少ない
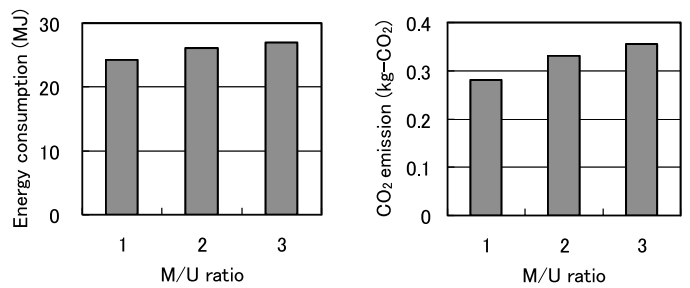

Fig. 3. Sensitivity analyses of energy consumption and $\mathrm{CO}_{2}$ emission for different $\mathrm{M} / \mathrm{U}$ ratios of MUF.
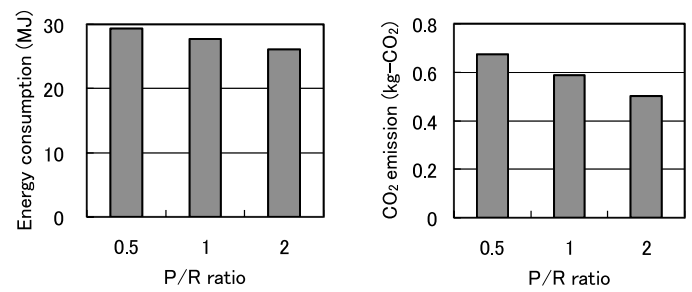

Fig. 4. Sensitivity analyses of energy consumption and $\mathrm{CO}_{2}$ emission for different $\mathrm{P} / \mathrm{R}$ ratios of PRF. 
UF の 6 倍以上と, 著しく大きく, ホルムアルデヒ ド対策に使われ始めた接着剤は環境負荷量の点から 問題のあることが分かった。

インベントリ分析より，接着剤の環境負荷量は主 原料と排出原単位の大きい原料に起因することが分 かった。さらに, MUF と PRF における M/U 比や $\mathrm{P} / \mathrm{R}$ 比を実用範囲で変えると, 環境負荷量は，接着 剂の順位が逆転するほど大きく変動することはない ものの，1～ 2 割程度と無視できないほど変化する ことが感度分析より分かったので，環境負荷量を低 減するには，主原料の配合比にも配慮する必要のあ ることが分かった。

今回得られた接着凨の環境負荷量は単位重量当た りのものであり，この結果により接着剤の環境負荷 に対する優劣を比較することはできない。すなわち, 接着剤は中間製品であることから，機能単位を揃え た木質材料について, 増量剤や硬化剂などの添加物 の評価も加えて, 環境負荷量を比較すべきであり, ここでは，そのための汎用性を持たせた木質材料用
接着剤の原単位を求めたものである。

\section{文献}

1）沖 慶雄：木材工業 53(1),7-13（1998）.

2）沖 慶雄：日本接着学会誌 32(11), 432-436 (1996).

3）富田文一郎：木材研究·資料 No. 35, 1-9 (1999).

4）田村靖夫, 宮崎泰顕：木材工業 25(4), 155-159 (1970).

5）田村靖夫, 宮崎泰顕：木材工業 25 (4), 215-219 (1970).

6）“接着ハンドブック”, 日本接着学会編, 日刊工 業新聞社, 東京, 1996, pp. 355-373, 396-415.

7）(社) 産業環境管理協会調査企画部：“JEMAILCA Ver. 1.1.6", 東京, 2003.

8）“内外化学品資料2001年版”, CMC 出版編, シー エムシー, 東京, 2002 .

9）(独）産業技術総合研究所 LCA 研究センター資 料. 